This item is the archived peer-reviewed author-version of:

\title{
Oximetry in obese children with sleep-disordered breathing
}

\section{Reference:}

Evangelisti Melania, Shafiek Hanaa, Rabasco Jole, Forlani Martina, Montesano Marilisa, Barreto Mario, Verhulst Stijn, Villa Maria Pia.- Oximetry in obese children with sleep-disordered breathing

Sleep medicine - ISSN 1389-9457 - 27-28(2016), p. 86-91

Full text (Publisher's DOI): http://dx.doi.org/doi:10.1016/J.SLEEP.2016.08.014

To cite this reference: http://hdl.handle.net/10067/1402640151162165141 


\section{Accepted Manuscript}

Oximetry in obese children with sleep-disordered breathing

Melania Evangelisti, Hanaa Shafiek, Jole Rabasco, Martina Forlani, Marilisa Montesano, Mario Barreto, Stijn Verhulst, Maria Pia Villa

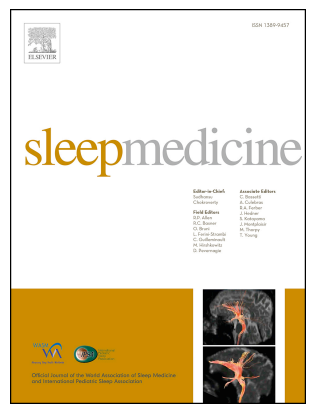

PII:

S1389-9457(16)30202-7

DOI:

10.1016/j.sleep.2016.08.014

Reference: SLEEP 3172

To appear in: Sleep Medicine

Received Date: 16 February 2016

Revised Date: 6 August 2016

Accepted Date: 8 August 2016

Please cite this article as: Evangelisti M, Shafiek $\mathrm{H}$, Rabasco J, Forlani M, Montesano M, Barreto M, Verhulst S, Villa MP, Oximetry in obese children with sleep-disordered breathing, Sleep Medicine (2016), doi: 10.1016/j.sleep.2016.08.014.

This is a PDF file of an unedited manuscript that has been accepted for publication. As a service to our customers we are providing this early version of the manuscript. The manuscript will undergo copyediting, typesetting, and review of the resulting proof before it is published in its final form. Please note that during the production process errors may be discovered which could affect the content, and all legal disclaimers that apply to the journal pertain. 


\section{Original Article}

\section{Oximetry in obese children with sleep-disordered breathing}

Melania Evangelisti ${ }^{\mathrm{a}}$, Hanaa Shafiek ${ }^{\mathrm{b}}$, Jole Rabasco ${ }^{\mathrm{a}}$, Martina Forlani ${ }^{\mathrm{a}}$, Marilisa Montesano ${ }^{\mathrm{a}}$, Mario Barreto ${ }^{a}$, Stijn Verhulst ${ }^{c}$, Maria Pia Villa ${ }^{\mathrm{a}, *}$

${ }^{\text {a }}$ Pediatric Sleep Disease Center, Child Neurology, NESMOS Department, School of Medicine and Psychology, Sapienza University of Rome, S. Andrea Hospital, Rome, Italy

${ }^{\mathrm{b}}$ Department of Chest Diseases, Faculty of Medicine, Alexandria University, Alexandria, Egypt

${ }^{\mathrm{c}}$ Department of Pediatric Pulmonology, Cystic Fibrosis Clinic and Pediatric Sleep Medicine, Antwerp University Hospital, Edegem, Belgium

\section{ARTICLE INFO}

Article history:

Received

Received in revised form

Accepted

Keywords:

Obesity

Obstructive sleep apnea

Oxygen desaturation. 
Corresponding author at: Pediatric Sleep Disease Center, Child Neurology, NESMOS Department,

School of Medicine and Psychology, Sapienza University of Rome, S. Andrea Hospital, Via di

Grottarossa 1035-39, 00189 Rome, Italy. Tel.: +39 0633775358; fax: +39 0633775941.

E-mail address: mariapia.villa@uniroma1.it (M.P. Villa). 
ABSTRACT

Background: Obesity is an important risk factor for obstructive sleep apnea syndrome (OSAS), and obese children with OSAS have frequently shown oxygen desaturations when compared with normal-weight children. The aim of our study was to investigate the oximetry characteristics in children with obesity and sleep-disordered breathing (SDB).

Methods: Children referred for suspected OSAS were enrolled in the study. All children underwent sleep clinical record (SCR), pulse oximetry, and polysomnography (PSG).

Results: A total of 248 children with SDB were recruited (128 obese and 120 normal-weight children). Obese children showed higher oxygen desaturation index (ODI) and lower nadir oxygen saturation (nadir $\mathrm{SaO}_{2}$ ) compared to non-obese children $(p<0.05)$. ODI and nadir $\mathrm{SaO}_{2}$ correlated with obesity $(p<0.05)$. The SCR evaluation showed that deep bite and overjet were more common among obese children $(p<0.05)$, whereas habitual nasal obstruction and arched palate were more common among non-obese children $(p<0.05)$. Furthermore, skeletal malocclusion and tonsillar hypertrophy were significant risk factors in obese children associated with severe desaturation $(p<$ $0.05)$.

Conclusion: Obese children with SDB have a more significant oxygen desaturation; adeno-tonsillar hypertrophy is not the only important risk factor for its development but also the presence of malocclusions. 


\section{Introduction}

Sleep-disordered breathing (SDB) in children comprises a wide spectrum ranging from primary snoring to obstructive sleep apnea syndrome (OSAS), which is the most severe entity of SDB. OSAS is characterized by a combination of repeated episodes of prolonged partial upper airway obstruction (obstructive hypopnea) and/or intermittent complete obstruction (obstructive apnea) that disturb normal sleep patter and normal ventilation during sleep, and result in disruption of normal gas exchange (intermittent hypoxia and hypercapnia) [1-3].

The prevalence of OSAS has been traditionally estimated to be $1-5.7 \%$ in the pediatric population $[4,5]$ and is primarily associated with adenotonsillar hypertrophy. The prominent increase in the prevalence and severity of overweight and obesity in children and adolescents in the last few decades worldwide [6,7] has translated into a parallel increase in the prevalence of OSAS [8]. Verhulst et al. found, in a recent study, that the prevalence of OSAS is much higher in obese children and has been reported to range between $13 \%$ and $59 \%$ [9]. The etiological factors predisposing to obesity-related OSAS remain to be determined, but an obesity phenotype in childhood OSAS, more close to the adult type, has been proposed [10,11] . This phenotype is associated primarily with obesity and milder adenotonsillar hyperplasia $[12,13]$, and the link between obesity and OSAS is associated with a chronic low-grade inflammatory state underlying some of the cognitive, metabolic, and cardiovascular morbidities [14,15]. Determining SDB severity in a child with relevant symptoms consistent with SDB is very important. It is reported that evaluation for SDB based mostly on clinical evaluation alone does not have sufficient specificity and sensitivity to establish a diagnosis of OSAS, and that the gold standard for the diagnosis of SDB is overnight polysomnography (PSG); however, this is also an expensive, time-consuming, and labor-intensive procedure [16] .

Therefore, alternative screening methods for OSAS are warranted, so that treatment can be started as soon as possible. Nocturnal oximetry has been proposed as an abbreviated and low-cost testing 
modality for the diagnosis of OSAS, and recently Kaditis et al. affirmed that this is a valuable tool that can facilitate treatment decisions when PSG is not available [17] . On the contrary, Van Eyck et al. suggested in their study that nocturnal oximetry alone is insufficient as a screening tool for OSAS in obese children [18].

The aim of our study was first to investigate the oximetry characteristics in OSAS children with and without obesity, and second, to determine whether obese children with OSAS have particular characteristics in term of clinical findings that are useful for diagnostic, therapeutic, and follow-up evaluations.

\section{Methods}

\subsection{Study design and population}

Consecutive out-patient children referred to our pediatric department (S. Andrea Hospital of Rome), between November 2013 and June 2015 for suspected OSAS, were enrolled in the study. Children with epilepsy or previous treatment of OSAS, acute or chronic cardiorespiratory or metabolic diseases, neuromuscular diseases, dysmorphism, major craniofacial abnormalities, or associated chromosomic syndromes were excluded from the study. A detailed personal and family history was obtained from all the participants, and a general clinical examination was performed. The height and weight of each child were measured using standard techniques. The weight (in kilograms) and height (in centimeters) were taken at presentation, and the body mass index (BMI) was calculated as well as the BMI percentile (pBMI) and BMI $z$ score. Children with pBMI greater than or equal to the 95th percentile were considered to be obese according to the International Obesity Task [19] . Moreover, all of the children underwent an ear, nose, and throat (ENT) and orthodontic assessment. All children underwent sleep clinical record (SCR), nocturnal oximetry, and PSG study. The diagnosis of OSAS was confirmed by the presence of SDB symptoms in combination with an apnea/hypopnea index (AHI) $\geq 1$ episode/h, according to the ERS statement on pediatric SDB [20] . 
A diagnosis of primary snoring was made in children who snored habitually and had an AHI of $<1$ episode/h.

The study protocol was approved by the local Ethics Committee, and written informed consent was obtained from the parents.

\subsection{Sleep clinical record}

All of the children underwent the sleep clinical record (SCR) evaluation previously validated by Villa et al. [16] . Briefly, SCR consists of three main items. The first item takes into consideration the data yielded by physical examination of the nose, oropharynx, and dental and skeletal occlusion. The following signs are considered: signs of oral breathing such as nasal cartilage hypotonia (low muscle tone of the muscles surrounding the nasal cartilage) or orbicular muscle hypotonia; nasal obstruction, considering nostril patency (analyzed by blocking one nostril with one finger followed by inspiration through the non-occluded nostril), inferior turbinate hypertrophy, or rhinolalia; pathologic palate position graded according to Friedman classes (grade 3 and 4 considered as positive) [21] ; nasal septum deviation; tonsillar hypertrophy (grades 3 and 4 were considered as tonsillar hypertrophy) [22] ; obese or adenoid phenotype; and dental/skeletal malocclusion and narrow palate. The dental/skeletal malocclusion or, in other words, intermaxillary divergence includes jaw deviation from normal occlusion as retrognathia (an abnormal posterior positioning of the maxilla), prognathia (protrusion of either of the jaws beyond a predetermined imaginary line in the coronal plane of the skull), open bite (the upper incisor crowns fail to overlap the lower incisor crowns), deep bite (the extent of vertical (superior-inferior) overlap of the maxillary central incisors over the mandibular central incisors), cross bite (a tooth (or teeth) has a more buccal or lingual position), and overjet (the extent of horizontal "anterior-posterior" overlap of the maxillary central incisors over the mandibular central incisors). These signs were scored as 2 points (positive sign) vs 0 point (negative sign). Second, a Brouillette score from the presented symptoms (mainly apnea, snoring, and restless sleep) was calculated considering a score greater 


\section{ACCEPTED MANUSCRIPT}

than or equal to -1 as positive [23] and scored as 0.5 . Third, the presence of symptoms of inattention and hyperactivity using the Attention-Deficit/Hyperactivity Disorder (ADHD) Rating Scale for School-Aged Children, adapted Italian version [24], was considered. A positive ADHD scale of $>6$ was considered as positive and scored as 1 . A total score of 6.5 was considered positive, as previously approved [16] .

\subsection{Nocturnal pulse oximetry}

The Nonin 2500A pulse oximeter (Nonin Medical; Plymouth, MN) was used to obtain nocturnal oximetry recordings. The oximeter was applied during a full night for at least 6 hours during sleep. A physician who was blinded to the patient's PSG analyzed the recordings using the PROXYnet 10.1 software package (MedicAir, Italia). The oxygen saturation $\left(\mathrm{SaO}_{2}\right)$ analysis parameters were adjusted as follows: percent $\mathrm{SaO}_{2}$ drop for event by at least $4 \%$ for minimum duration of 8 seconds. Autoanalysis was done by the software after reviewing the whole recording and excluding the parts the readings' cut-off. A McGill Oximetry Score of 1-4 was assigned to each oximetry recording [25]. In summary, oximetry recordings with three or more clusters of desaturation events and three or more dips in $\mathrm{SaO}_{2}$ below $90 \%$ were regarded as diagnostic for OSAS (abnormal or positive oximetry). Recordings not meeting these diagnostic criteria were considered as negative/nonconclusive for OSAS [26] .

\subsection{Polysomnography}

All children underwent laboratory overnight PSG assessment using a Grass Heritage polygraph (Natus Neurology Incorporated-Grass Products, Warwick, RI, USA). Sleep stages were scored according to the standard criteria of the AASM after being subdivided into 30-second epochs. Arousals were detected visually according to the criteria reported in the AASM Manual for the Scoring of Sleep and Associated Events [27] . 
Central, obstructive, and mixed apnea events were counted according to the criteria established by the AASM [27] . Chest and abdominal movements were measured by strain gauges. Oronasal airflow was recorded by means of a thermocouple and nasal pressure. Arterial oxygen saturation was monitored with pulse oximetry. The AHI was defined as the average number of apneas and hypopneas per hour of sleep. All recordings started at the patients' usual bedtime and continued until spontaneous awakening. All recordings were scored visually by one of the investigators, who were blinded to the subjects' group, age and sex. The diagnosis of OSAS was confirmed by means of a laboratory PSG revealing an AHI $\geq 1$ episode/h, in combination with symptoms of SDB [20] . Primary snoring (PS) was diagnosed in children with habitual snoring, an AHI $<1$ episode/h, and microphone-detected snoring.

\subsection{Statistical analysis}

All variables were tested for normality. Accordingly, the values are expressed as number and percentage $(\%)$ for categorical variables and mean \pm standard deviation $(\mathrm{SD})$ or median and interquartile range $(\mathrm{IQR}=25$ th -75 th percentile $)$ for continuous variables according to data distribution of normality. A $\chi^{2}$ test or Fisher exact test were used for categorical variables and an independent $t$ test or Mann-Whitney test for continuous variables according to the normal distribution of the available data. A Spearman rho correlation was used to investigate the variables of interest. A receiver operating characteristic (ROC) curve and area under the curve (AUC) were used to calculate the sensitivity, specificity, positive predictive value (PPV), and negative predictive value (NPV) of the oxygen desaturation index (ODI) for predicting OSA. Univariate and multivariate logistic regression hazard analysis was applied to study different parameters of the SCR and oximetry parameters in relation to obesity. The hazard ratio and $95 \%$ confidence interval (CI) were shown. All the conducted tests were two-tailed, and a $p$ value of $<0.05$ was considered as significant. The SPSS software package (PASW Statistics for Windows, Version 18.0; SPSS Inc., Chicago, IL, USA) was used for all current analyses. 


\section{Results}

The characteristics of the recruited children are summarized in Table 1; a total of 248 children with SDB were recruited (128 obese children and 120 normal-weight children). Considering that AHI $\geq$ 1 episode/h in combination with SDB symptoms indicated the presence of OSAS, $79.7 \%$ of the obese children had OSAS, and $20.3 \%$ were habitual snorers; and $79.2 \%$ of non-obese children had OSAS, and $20.8 \%$ were habitual snorers, without a significant difference between groups (Table 1). Both groups had normal central apnea index, and no differences were found between groups (obese: $0.13 \pm 0.25$ vs non-obese: $0.13 \pm 0.23$ episodes/h, $p=0.93$ ).

The median BMI, pBMI, and BMI $z$ score among the obese children was significantly higher than that in non-obese children $(p<0.0001)$. There was no statistical difference regarding age, sex, and SCR score among the obese and non-obese children, as well as the duration of symptoms $(p>$ 0.05). The median ODI was significantly higher among the obese children (4.9 [IQR $=3.8-7.1]$ vs $4.3[\mathrm{IQR}=3.1-6.45]$ episodes/h; $p=0.033$; Fig. 1). In addition, the nadir $\mathrm{SaO}_{2}$ was significantly lower among the obese children compared to the non-obese children $(88.0 \%$ [IQR $=85.0-91.0 \%)$ vs $90 \%[\mathrm{IQR}=84.0-92.0 \%)] ; p=0.038$, with a similar median of minimum $\mathrm{SaO}_{2}$ for both groups

(Table 1). However, in both groups, a McGill score of 1 was the most prevalent (>85\% of the cases), whereas the inconclusive oximeter study yielded $53.6 \%$ and $48.3 \%$ among obese and nonobese children respectively. When we performed the correlations, pBMI inversely correlated with nadir $\mathrm{SaO}_{2}(r=-0.144, p=0.025)$ and positively correlated with ODI $(r=0.142, p=0.026)$. In Table 2 we reported the oximetry and PSG parameters in the obese and non-obese subgroups, depending on the presence of OSAS. The obese children with PS showed a significantly higher ODI $(p=0.014)$, a lower average minimum $\mathrm{SaO}_{2}(p=0.018)$, and lower average $\mathrm{SaO}_{2}(p=0.036)$ than the non-obese children with PS.

The median of average $\mathrm{SaO}_{2}$ among the OSAS obese subgroup was significantly higher than among obese PS subgroup $(97.3 \%$ [IQR= 96.6-97.7\%] vs 96.4\% [IQR $=95.4-97.4 \%] ; p=0.01)$. 
Moreover, the median of average minimum $\mathrm{SaO}_{2}$ was higher among the OSAS obese subgroup compared to the habitual snoring obese subgroup $(95.1 \%$ [IQR $=94.2-95.8 \%]$ vs $94.3 \%$ [IQR $=$ 93.3-95\%], $p=0.025$; Table 2). Furthermore, the median age of onset of OSAS obese subgroup was significantly higher than among obese PS subgroup (4.0 vs 1.0 years, $p=0.03$; Table 2 ). The OSAS obese subgroup differed significantly from the non-obese OSAS subgroup regarding the duration of OSAS symptoms (2.8 vs 4.3 years, $p<0.03$ ), the age of SDB onset (4.0 vs 1.0 years, $p$ $<0.0001)$, and the nadir $\mathrm{SaO}_{2}(87.5$ vs $90 \%, p=0.04)$.

The SCR among the recruited patients showed that both the deep bite and the overjet were more common skeletal malocclusions among the school-aged obese children $(42.4 \%, p=0.031$ and $20 \%$, $p=0.024$ respectively), whereas habitual nasal obstruction and arched palate were more common among the school aged non-obese children $(73.7 \%, p=0.002$ and $84.2 \%, p=0.003$ respectively). Univariate logistic regression analysis showed that oral breathing and tonsillar hypertrophy were significant risk factors for development of OSAS among obese children, with hazard ratio of $1.69(p$ $=0.014 ; 95 \%$ confidence interval $[\mathrm{CI}]=1.11-2.56)$ and $1.65(p=0.016 ; 95 \% \mathrm{CI}=1.1-2.48)$, respectively. On the other hand, the presence of retrognathia or hypognathia showed a hazard ratio of $2.2(95 \% \mathrm{CI}=0.86-5.55)$ for development of OSAS among obese children despite being statistically insignificant $(p=0.102)$. Furthermore, obesity was the only significant risk factor in the whole studied population (ie, both obese and non-obese children) for the development of severe desaturation $(\leq 88 \%)$, with a hazard ratio of $1.83(95 \% \mathrm{CI}=1.1-3.05, p=0.019)$, whereas skeletal malocclusion and tonsillar hypertrophy were significant risk factors in obese children associated with severe desaturation, with a hazard ratio of $3.9(95 \% \mathrm{CI}=1.2-12.3, p=0.02)$ and $1.6(95 \% \mathrm{CI}$ $=1.01-2.6 ; p=0.047)$, respectively.

We observed that $64.7 \%$ (66/102 children) with ODI $>4 / \mathrm{h}$ and $35.3 \%$ (36/102 children) with ODI $<4 / \mathrm{h}$ had OSAS in the obese subgroup (Table 2). However, the majority of the obese OSAS children with ODI < 4/h (28/36 children, 77.7\%) had mild OSAS (ie, AHI < 5 episodes/h). 
Using the ROC curve, ODI $>4 / \mathrm{h}$ showed the best sensitivity $(72 \%)$ for predicting OSAS in obese children after excluding very minimal OSAS (ie, ranging from $\geq 1$ to $<2$ ) and PPV of $68 \%$; however, it had a low specificity of $41 \%$ and an NPV of $46 \%$ (Table 3 ). Similarly, ODI $>4 / \mathrm{h}$ had a sensitivity of $73 \%$ in detecting mild-to-moderate OSAS (ie, AHI $\geq 2$ to $<10$ episodes/h), with a low specificity of $37 \%$ (Table 3 ).

However, the sensitivity of ODI $>4 / \mathrm{h}$ in obese children improved to $84 \%$ for predicting moderateto-severe OSAS (ie, AHI $\geq 5$ episodes/h) (Table 3). We observed also that obese children with ODI $>4$ were at twice the risk for having OSA (95\% CI $=0.7-5.7)$ despite non-significance $(p=0.217)$. Based on this index, both angle malocclusion and oral breathing were significant risk factors for $\mathrm{t}$ he development of OSA among obese children, with hazard ratio of $2.89(p=0.011 ; 95 \% \mathrm{CI}=$ $1.27-6.55)$ and $1.86(p=0.01 ; 95 \% \mathrm{CI}=1.17-2.96)$, respectively. On the contrary, ODI > 4 was not a risk factor for having OSA in non-obese children (hazard ratio $=1.2$ ), and it showed a low sensitivity of $58 \%$ in predicting OSAS in the non-obese children (Table 3). Regarding the McGill oximetry score, a score $\geq 2$ had a sensitivity of $14 \%$ and $15 \%$ for predicting OSAS in obese and nonobese children, respectively, with a high specificity ( $83 \%$ and $100 \%$, respectively; Table 3 ). Furthermore, $51 \%$ of the McGill score 1 were mild-to-moderate OSAS and $18 \%$ were severe OSAS in the obese children.

\section{Discussion}

In the current study, we observed that the obese children with SDB showed a lower nadir $\mathrm{SaO}_{2}$, and higher ODI than non-obese children. These pulse oximetry parameters correlated closely with obesity. Moreover, tonsillar hypertrophy, oral breathing, and malocclusions were the most important clinical characteristics linked to obesity.

Structural changes in the upper airway, adeno-tonsillar hypertrophy, and excess fat deposition around the pharynx may be responsible for the increased risk of OSA in obese children $[28,29]$. 
Verhulst et al. found the presence of OSAS in $19 \%$ of obese subjects and in $41 \%$ of overweight subjects, with no correlation between the BMI $z$ score and obstructive AHI; but they observed significant associations between $\mathrm{BMI}$ and both mean and nadir $\mathrm{SaO}_{2}$ [9] . In our sample, children with obesity were younger than those in the above-mentioned study, and even in the conditions of primary snoring, a lower mean $\mathrm{SaO}_{2}$ and nadir $\mathrm{SaO}_{2}$ and a higher ODI were reported when compared with those in non-obese children. These aspects were associated with the greater age of symptom onset and the shorter duration of OSAS symptoms in obese children with OSAS. Early diagnosis and treatment are mandatory to avoid the damage caused by SDB-associated intermittent hypoxia and the development of neurocognitive and cardiovascular complications [30-34] . Furthermore, we found that the frequencies of OSAS and McGill oximetry score were similar in obese and non-obese children rather than those previously reported in the literature [9]. This could be explained first on the basis that the children involved in the current study were recruited from our Pediatric Sleep Disease Center and not randomly from the community. Second, all of these children presented with symptoms of OSAS, and they were further divided according to pBMI into obese and non-obese. Vitelli et al. [35] evaluated the impact of obesity on intelligence quotient (IQ) in children with OSAS, and they demonstrated that obesity is an important risk factor for developing cognitive impairment. In this view, the obese children with OSAS have greater risk of damage from intermittent hypoxia, and they should be screened for SDB as soon as possible. When PSG studies are not available, the pulse oximetry, linked to the clinical examination, could help in the evaluation of these children, and the finding of intermittent oxygen desaturations during sleep is highly suggestive of the presence and severity of OSAS $[17,26]$.

Multiple other factors may be responsible for the increased risk of OSAS in obese children and adolescents, such as the pulmonary function abnormalities. Obesity may result in central adiposity and an excess mechanical load on the chest wall, which in turn can result in reduced functional residual capacity and tidal volumes [36,37] . Van Eyck et al., in a recent study [36] , demonstrated in obese children with OSAS that RDI and ODI correlated with diminished lung function, and the 
desaturation during sleep was associated with a more restrictive lung function. Although these respiratory findings correlated with the severity of OSAS, the level of obesity remains an important confounding factor as well. The classical risk factor for obstructive SDB in normal-weight children is an enlargement of the adenoids and/or tonsils, with a peak age of incidence between 2 and 8 years [10] . Obese children with OSAS tend to be older and to have less lymphoid hyperplasia, and are at increased risk for cardiovascular and metabolic dysfunction than their lean counterparts who have OSAS $[10,38]$.

In the NANOS study [14], the authors observed that obese children with OSAS had smaller adenotonsillar tissues compared to non-obese OSAS children matched for age, sex, ethnicity, and obstructive AHI, although their Mallampati scores were higher. This indicates that the presence of obesity increases the risk for OSAS not only by increased lymphadenoid tissue proliferation but also by restricting the overall pharyngeal space [10] .

In the study by Dayyat et al. [10] , the authors conclusively demonstrated that for any level of OSAS severity the habitually snoring obese children required less adeno-tonsillar hypertrophy when compared to non-obese children of the same age, sex, and ethnicity. These differences appear to be mediated, at least in part, by the presence of a more crowded airway in obese children, as a corollary to increased fat deposits in the airway [10] . In obese patients who have a distribution of the body fat mainly over the upper part of their body, the resistance of the upper airway during sleep tends to be very high $[28,29,39]$.

In a recent review of adult patients with OSAS, Cuccia et al. [39] found that in non-obese as well as obese OSAS adult patients, skeletal changes are often evident, especially in obese individuals (in terms of intermaxillary divergence). Cephalometric surveys of children with OSA have overall suggested the presence of selected alterations in the dimensions and vectors of several craniofacial skeletal structures $[40,41]$.

To our knowledge, no previous study has investigated the prevalence of malocclusions in obese children with OSAS. In our study, skeletal malocclusions did not differ between obese and non- 
obese children with SDB except for deep bite and overjet, which were significantly more common in obese school-aged children. However, malocclusions correlated with the oximetry parameters in obese children. These findings suggest that not only the adeno-tonsillar hypertrophy but also the presence of malocclusions is an important risk factor for SDB development in obese children, and these findings should be considered in the treatment of these individuals.

\section{Conclusions}

Defining abnormalities in the pulse oximetry of obese children, with the presence of possible risk factors for OSAS (not only adeno-tonsillar hypertrophy) could be used for an early diagnosis of SBD and guiding treatment when PSG study is not available. It is very important to intercept obese children with SDB as soon as possible for more effective treatment in order to prevent neurocognitive, cardiovascular, and metabolic complications. 


\section{Conflict of interest}

None of the authors has any potential conflicts of interest involving this work. 


\section{References}

[1] Tauman R, Gozal D. Obstructive sleep apnea syndrome in children. Expert Rev Respir Med 2011;5:425-40.

[2] Marcus CL, Brooks LJ, Draper KA, Gozal D, Halbower AC, Jones J, et al. Diagnosis and management of childhood obstructive sleep apnea syndrome. Pediatrics 2012;130:e714-55.

[3] Leiberman A, Stiller-Timor L, Tarasiuk A, Tal A. The effect of adenotonsillectomy on children suffering from obstructive sleep apnea syndrome (OSAS): The Negev perspective. Int $\mathbf{J}$ Pediatr Otorhinolaryngol 2006;70:1675-82.

[4] Almeida LA, Anselmo-Lima WT, Valera FC. OSAS in children: Where are we? Braz J Otorhinolaryngol 2011;77:273.

[5] Powell S, Kubba H, O'Brien C, Tremlett M. Paediatric obstructive sleep apnoea. BMJ 2010;340:c1918.

[6] Lobstein T, Baur L, Uauy R. Obesity in children and young people: A crisis in public health. Obes Rev 2004;5(Suppl 1):4-104.

[7] Wijnhoven TM, van Raaij JM, Spinelli A, Rito AI, Hovengen R, Kunesova M, et al. WHO European Childhood Obesity Surveillance Initiative 2008: Weight, height and body mass index in 6-9-year-old children. Pediatr Obes 2013;8:79-97.

[8] Redline S, Tishler PV, Schluchter M, Aylor J, Clark K, Graham G. Risk factors for sleepdisordered breathing in children. Associations with obesity, race, and respiratory problems. Am J Respir Crit Care Med 1999;159:1527-32.

[9] Verhulst SL, Van Gaal L, De Backer W, Desager K. The prevalence, anatomical correlates and treatment of sleep-disordered breathing in obese children and adolescents. Sleep Med Rev 2008; 12:339-46. 
[10] Dayyat E, Kheirandish-Gozal L, Sans Capdevila O, Maarafeya MM, Gozal D. Obstructive sleep apnea in children: Relative contributions of body mass index and adenotonsillar hypertrophy. Chest 2009;136:137-44.

[11] Hakim F, Kheirandish-Gozal L, Gozal D. Obesity and altered sleep: A pathway to metabolic derangements in children? Semin Pediatr Neurol 2015;22:77-85.

[12] Dayyat E, Kheirandish-Gozal L, Gozal D. Childhood obstructive sleep apnea: One or two distinct disease entities? Sleep Med Clin 2007;2:433-44.

[13] Capdevila OS, Kheirandish-Gozal L, Dayyat E, Gozal D. Pediatric obstructive sleep apnea: Complications, management, and long-term outcomes. Proc Am Thorac Soc 2008;5:274-82.

[14] Alonso-Alvarez ML, Cordero-Guevara JA, Teran-Santos J, Gonzalez-Martinez M, JuradoLuque MJ, Corral-Penafiel J, et al. Obstructive sleep apnea in obese community-dwelling children: The NANOS study. Sleep 2014;37:943-9.

[15] Gileles-Hillel A, Alonso-Alvarez ML, Kheirandish-Gozal L, Peris E, Cordero-Guevara JA, Teran-Santos J, et al. Inflammatory markers and obstructive sleep apnea in obese children: The NANOS study. Mediators Inflamm 2014;2014:605280.

[16] Villa MP, Paolino MC, Castaldo R, Vanacore N, Rizzoli A, Miano S, et al. Sleep clinical record: An aid to rapid and accurate diagnosis of paediatric sleep disordered breathing. Eur Respir $\mathbf{J}$ 2013;41:1355-61.

[17] Kaditis A, Kheirandish-Gozal L, Gozal D. Pediatric OSAS: Oximetry can provide answers when polysomnography is not available. Sleep Med Rev 2015 Jun 4.

[18] Van Eyck A, Lambrechts C, Vanheeswijck L, Van Hoorenbeeck K, Haentjens D, Boudewyns A, et al. The role of nocturnal pulse oximetry in the screening for obstructive sleep apnea in obese children and adolescents. Sleep Med 2015;16:1409-12.

[19] Cole TJ, Bellizzi MC, Flegal KM, Dietz WH. Establishing a standard definition for child overweight and obesity worldwide: International survey. BMJ 2000;320:1240-3. 
[20] Kaditis AG, Alonso Alvarez ML, Boudewyns A, Alexopoulos EI, Ersu R, et al. Obstructive sleep disordered breathing in 2- to 18-year-old children: Diagnosis and management. Eur Respir J 2016;47:69-94.

[21] Friedman M, Ibrahim H, Joseph NJ. Staging of obstructive sleep apnea/hypopnea syndrome: A guide to appropriate treatment. Laryngoscope 2004;114:454-9.

[22] Liistro G, Rombaux P, Belge C, Dury M, Aubert G, Rodenstein DO. High Mallampati score and nasal obstruction are associated risk factors for obstructive sleep apnoea. Eur Respir J $2003 ; 21: 248-52$.

[23] Brouilette R, Hanson D, David R, Klemka L, Szatkowski A, Fernbach S, et al. A diagnostic approach to suspected obstructive sleep apnea in children. J Pediatr 1984;105:10-4.

[24] Marzocchi GM CC. Una scala di facile uso per la rilevazione dei comportamenti problematici dei bambini con Deficit di Attenzione e Iperattivita`. [A scale to indentify behavioural problems in ADHD children.]. Psicologia Clinica dello Sviluppo 2000:43-64.

[25] Nixon GM, Kermack AS, Davis GM, Manoukian JJ, Brown KA, Brouillette RT. Planning adenotonsillectomy in children with obstructive sleep apnea: The role of overnight oximetry. Pediatrics 2004;113:e19-25.

[26] Brouillette RT, Morielli A, Leimanis A, Waters KA, Luciano R, Ducharme FM. Nocturnal pulse oximetry as an abbreviated testing modality for pediatric obstructive sleep apnea. Pediatrics 2000;105:405-12.

[27] Iber C, Ancoli-Israel S, Chesson AL, Quan SF. The AASM Manual for the Scoring of Sleep and Associated Events: Rules, Terminology, and Technical Specifications. 1st ed. Westchester, American Academy of Sleep Medicine; 2007.

[28] Wing YK, Hui SH, Pak WM, Ho CK, Cheung A, Li AM, et al. A controlled study of sleep related disordered breathing in obese children. Arch Dis Child 2003;88:1043-7. 
[29] Arens R, Sin S, Nandalike K, Rieder J, Khan UI, Freeman K, et al. Upper airway structure and body fat composition in obese children with obstructive sleep apnea syndrome. Am J Respir Crit Care Med 2011;183:782-7.

[30] Marcus CL, Greene MG, Carroll JL. Blood pressure in children with obstructive sleep apnea. Am J Respir Crit Care Med 1998;157:1098-103.

[31] Amin RS, Kimball TR, Bean JA, Jeffries JL, Willging JP, Cotton RT, et al. Left ventricular hypertrophy and abnormal ventricular geometry in children and adolescents with obstructive sleep apnea. Am J Respir Crit Care Med 2002;165:1395-9.

[32] O'Brien LM, Gozal D. Neurocognitive dysfunction and sleep in children: From human to rodent. Pediatr Clin North Am 2004;51:187-202.

[33] Ryan S, McNicholas WT. Intermittent hypoxia and activation of inflammatory molecular pathways in OSAS. Arch Physiol Biochem 2008;114:261-6.

[34] Beebe DW, Gozal D. Obstructive sleep apnea and the prefrontal cortex: Towards a comprehensive model linking nocturnal upper airway obstruction to daytime cognitive and behavioral deficits. J Sleep Res 2002;11:1-16.

[35] Vitelli O, Tabarrini A, Miano S, Rabasco J, Pietropaoli N, Forlani M, et al. Impact of obesity on cognitive outcome in children with sleep-disordered breathing. Sleep Med 2015;16:62530.

[36] Van Eyck A, Van Hoorenbeeck K, De Winter BY, Van Gaal L, De Backer W, Verhulst SL. Sleep-disordered breathing and pulmonary function in obese children and adolescents. Sleep Med 2014;15:929-33.

[37] Narang I, Mathew JL. Childhood obesity and obstructive sleep apnea. J Nutr Metab 2012;2012:134202.

[38] Tan HL, Gozal D, Kheirandish-Gozal L. Obstructive sleep apnea in children: A critical update. Nat Sci Sleep 2013;5:109-23. 
[39] Cuccia AM, Campisi G, Cannavale R, Colella G. Obesity and craniofacial variables in subjects with obstructive sleep apnea syndrome: Comparisons of cephalometric values. Head Face Med 2007;3:41.

[40] Marino A, Malagnino I, Ranieri R, Villa MP, Malagola C. Craniofacial morphology in preschool children with obstructive sleep apnoea syndrome. Eur J Paediatr Dent 2009;10:181-4. [41] Kheirandish-Gozal L, Gozal D. Genotype-phenotype interactions in pediatric obstructive sleep apnea. Respir Physiol Neurobiol 2013;189:338-43. 


\section{Table 1}

Comparison between the clinical and demographic data among obese and non-obese children.

\begin{tabular}{|c|c|c|c|}
\hline Variable & $\begin{array}{l}\text { Obese } \\
(n=128)\end{array}$ & $\begin{array}{l}\text { Non-obese } \\
(n=120)\end{array}$ & $\begin{array}{l}\text { Significance } \\
(p)\end{array}$ \\
\hline Age (y) & $8.08(5.54-10.33)$ & $6.75(4.71-9.0)$ & NS \\
\hline $\begin{array}{l}\text { Age group }(y) \\
\geq 6 \\
<6\end{array}$ & $\begin{array}{l}85(66.4) \\
43(33.6)\end{array}$ & $\begin{array}{l}76(63.3) \\
44(36.7)\end{array}$ & NS \\
\hline Sex (male/female) & $93(72.7) / 35(27.3)$ & $74(61.7) / 46(38.3)$ & $\mathrm{NS}$ \\
\hline BMI & $24.04(20.3-27.4)$ & $16.6(15.15-18.4)$ & $<0.0001$ \\
\hline pBMI & $105.5(99.0-119.5)$ & $61.0(30.0-82.5)$ & $<0.0001$ \\
\hline BMI $z$ score & $2.2(1.9-2.4)$ & $0.3(-0.4$ to 1.2$)$ & $<0.0001$ \\
\hline Duration of OSA symptoms (y) & $2.75(1.01-5.8)$ & $4.04(2.41-6.0)$ & NS \\
\hline Age of SDB onset (y) & $4.0(1.0-7.0)$ & $1.25(1-3)$ & $<0.0001$ \\
\hline SCR total score & $8.0(6.0-9.0)$ & $8.5(6.5-8.75)$ & $\mathrm{NS}$ \\
\hline Positive SCR & $87(68)$ & $95(79.2)$ & NS \\
\hline AHI (ep/h) & $2.85(1.3-9.45)$ & $3.4(1.15-7.0)$ & NS \\
\hline OSA; yes/no (AHI $\geq 1)$ & $102(79.7) / 26(20.3)$ & $95(79.2) / 25(20.8)$ & NS \\
\hline Oximeter data & & +2 & \\
\hline ODI & $4.9(3.8-7.1)$ & $4.3(3.1-6.45)$ & 0.03 \\
\hline Average $\mathrm{SaO}_{2}(\%)$ & $97.2(96.5-97.7)$ & $97.15(96.6-97.7)$ & NS \\
\hline Nadir $\mathrm{SaO}_{2}(\%)$ & $88.0(85.0-91.0)$ & $90.0(84.0-92.0)$ & 0.04 \\
\hline Average of $\mathrm{Min} . \mathrm{SaO}_{2}(\%)$ & $95.0(93.9-95.8)$ & $95.0(94.15-95.8)$ & NS \\
\hline $\begin{array}{l}\text { McGill score } \\
\text { Score } 1 \\
\text { Score } 2 \\
\text { Score } 3 \\
\text { Score } 4\end{array}$ & $\begin{array}{l}107(85.6) \\
11(8.8) \\
2(1.6) \\
5(4)\end{array}$ & $\begin{array}{l}106(88.3) \\
7(5.8) \\
6(5) \\
1(0.8)\end{array}$ & NS \\
\hline $\begin{array}{l}\text { Oximeter reference } \\
\text { Negative } \\
\text { Non-conclusive } \\
\text { Positive }\end{array}$ & $\begin{array}{l}40(32) \\
67(53.6) \\
18(14.4)\end{array}$ & $\begin{array}{l}48(40) \\
58(48.3) \\
14(11.7)\end{array}$ & NS \\
\hline
\end{tabular}


Table 2

Comparison between OSAS and primary snoring (PS) in recruited patients.

\begin{tabular}{|c|c|c|c|c|c|c|c|}
\hline \multirow[t]{2}{*}{ Variable } & \multicolumn{2}{|c|}{ Primary snoring } & \multirow[b]{2}{*}{$p$} & \multicolumn{2}{|l|}{ OSAS } & \multirow[b]{2}{*}{$p$} & \multirow[b]{2}{*}{$\begin{array}{l}\text { Obese } \\
\text { PS vs } \\
\text { OSAS } \\
(p)\end{array}$} \\
\hline & $\begin{array}{l}\text { Non- } \\
\text { obese } \\
(n=25 \\
20.8 \%)\end{array}$ & $\begin{array}{l}\text { Obese } \\
(n=26 ; \\
20.3 \%)\end{array}$ & & $\begin{array}{l}\text { Non-obese } \\
(n=95 \\
79.2 \%)\end{array}$ & $\begin{array}{l}\text { Obese } \\
(n=102 ; \\
79.7 \%)\end{array}$ & & \\
\hline Age (y) & $7.0 \pm 3.1$ & $7.2 \pm 3.6$ & NS & $7.1 \pm 3.2$ & $8.0 \pm 2.9$ & 0.04 & NS \\
\hline $\begin{array}{l}\text { Age group }(y) \\
\geq 6 \\
<6\end{array}$ & $\begin{array}{l}12(48) \\
13(52)\end{array}$ & $\begin{array}{l}13(50) \\
13(50)\end{array}$ & NS & $\begin{array}{l}64(67.3) \\
31(32.6)\end{array}$ & $\begin{array}{l}72(70.6) \\
30(29.4)\end{array}$ & NS & NS \\
\hline Sex; male/female & $\begin{array}{l}14(56) / \\
11(44)\end{array}$ & $\begin{array}{l}20(76.9) / \\
6(23.1)\end{array}$ & NS & $\begin{array}{l}60(63.1) / \\
35(36.9)\end{array}$ & $\begin{array}{l}73(71.6) / \\
29(28.4)\end{array}$ & NS & NS \\
\hline BMI $\left(\mathrm{kg} / \mathrm{m}^{2}\right)$ & $\begin{array}{l}16.7 \\
(15-18.4)\end{array}$ & $\begin{array}{l}22.3 \\
(19.5- \\
28.7)\end{array}$ & $\begin{array}{l}<0.00 \\
1\end{array}$ & $\begin{array}{l}16.5 \\
(15.2- \\
18.6)\end{array}$ & $\begin{array}{l}24.3 \\
(20.4- \\
27.4)\end{array}$ & $<0.001$ & NS \\
\hline $\mathrm{pBMI}$ & $\begin{array}{l}60 \\
(29-85)\end{array}$ & $\begin{array}{l}110 \\
(102-118)\end{array}$ & $\begin{array}{l}<0.00 \\
1\end{array}$ & $\begin{array}{l}63 \\
(30-83)\end{array}$ & $\begin{array}{l}104 \\
(99-121)\end{array}$ & $<0.001$ & NS \\
\hline BMI $z$ score & $\begin{array}{l}-0.01 \\
(-0.6 \text { to } \\
1.2)\end{array}$ & $\begin{array}{l}2.2 \\
(1.9-2.6)\end{array}$ & $\begin{array}{l}<0.00 \\
1\end{array}$ & $\begin{array}{l}0.4 \\
(-0.5 \text { to } \\
1.2)\end{array}$ & $\begin{array}{l}2.1 \\
(1.9-2.4)\end{array}$ & $<0.001$ & NS \\
\hline $\begin{array}{l}\text { Duration of } \\
\text { OSAS symptoms } \\
\text { (y) }\end{array}$ & $\begin{array}{l}2.9 \\
(0.75-4.1)\end{array}$ & $\begin{array}{l}2.75 \\
(1-4.9)\end{array}$ & NS & $\begin{array}{l}4.3 \\
(2.4-6.0)\end{array}$ & $\begin{array}{l}2.8 \\
(1.1-5.8)\end{array}$ & 0.03 & NS \\
\hline $\begin{array}{l}\text { Age of SDB } \\
\text { onset }(y)\end{array}$ & $\begin{array}{l}2.0 \\
(1-2.5)\end{array}$ & $\begin{array}{l}1.0 \\
(0.2-5.0)\end{array}$ & NS & $\begin{array}{l}1.0 \\
(1-3)\end{array}$ & $\begin{array}{l}4.0 \\
(2.0-7.7)\end{array}$ & $<0.001$ & 0.03 \\
\hline ODI & $\begin{array}{l}4.3 \\
(2.6-5.5)\end{array}$ & $\begin{array}{l}5.9 \\
(4.2-7.9)\end{array}$ & 0.01 & $\begin{array}{l}4.3 \\
(3.1-6.6)\end{array}$ & $\begin{array}{l}4.75 \\
(3.8-7.0)\end{array}$ & NS & NS \\
\hline $\begin{array}{l}\text { Average } \mathrm{SaO}_{2} \\
(\%)\end{array}$ & $\begin{array}{l}97.4 \\
(96.5-97.8 \\
\end{array}$ & $\begin{array}{l}96.4 \\
(95.4-97.4\end{array}$ & 0.04 & $\begin{array}{l}97.1 \\
(96.6-97.7 \\
\end{array}$ & $\begin{array}{l}97.3 \\
(96.6- \\
97.7)\end{array}$ & NS & 0.01 \\
\hline Nadir $\mathrm{SaO}_{2}(\%)$ & $\begin{array}{l}90 \\
(84-92)\end{array}$ & $\begin{array}{l}89 \\
(87-90)\end{array}$ & NS & $\begin{array}{l}90 \\
(84-92)\end{array}$ & $\begin{array}{l}87.5 \\
(85-91)\end{array}$ & 0.04 & NS \\
\hline $\begin{array}{l}\text { Average Min. } \\
\mathrm{SaO}_{2} \\
(\%)\end{array}$ & $\begin{array}{l}95.4 \\
(94.1-6.3)\end{array}$ & $\begin{array}{l}94.3 \\
(93.3-95)\end{array}$ & 0.02 & $\begin{array}{l}94.9 \\
(94.1-95.6 \\
)\end{array}$ & $\begin{array}{l}95.1 \\
(94.2- \\
95.8)\end{array}$ & NS & 0.02 \\
\hline ODI > $4 ; n(\%)$ & $13(52)$ & $18(69.2)$ & NS & $55(58)$ & $66(64.7)$ & NS & NS \\
\hline $\begin{array}{c}\text { McGill score } \\
\text { Score } 1 \\
\text { Score } 2 \\
\text { Score } 3 \\
\text { Score } 4 \\
\end{array}$ & $\begin{array}{l}25(100) \\
0(0) \\
0(0) \\
0(0)\end{array}$ & $\begin{array}{l}26(100) \\
0(0) \\
0(0) \\
0(0)\end{array}$ & NS & $\begin{array}{l}81(85.2) \\
7(7.4) \\
6(6.4) \\
1(1.0)\end{array}$ & $\begin{array}{l}88(86.2) \\
8(7.8) \\
2(2.0) \\
4(4.0)\end{array}$ & NS & NS \\
\hline
\end{tabular}




\begin{tabular}{|c|c|c|c|c|c|c|c|}
\hline $\begin{array}{l}\text { Oximeter } \\
\text { reference } \\
\text { Negative } \\
\text { Inconclusive } \\
\text { Positive }\end{array}$ & $\begin{array}{l}12(48.0) \\
13(52.0) \\
0(0)\end{array}$ & $\begin{array}{l}3(11.5) \\
23(88.5) \\
0(0)\end{array}$ & 0.01 & $\begin{array}{l}36(37.9) \\
45(47.3) \\
14(14.7)\end{array}$ & $\begin{array}{l}37(36.3) \\
51(50.0) \\
14(13.7)\end{array}$ & NS & NS \\
\hline AHI (ep/h) & $\begin{array}{l}0.4 \\
(0.15-0.6)\end{array}$ & $\begin{array}{l}0.5 \\
(0.3-0.8)\end{array}$ & NS & $\begin{array}{l}4.6 \\
(2.0-9.5)\end{array}$ & $\begin{array}{l}4.1 \\
(2.2-12.4)\end{array}$ & NS & $<0.001$ \\
\hline SCR score & $\begin{array}{l}8.5 \\
(5.5-8.5)\end{array}$ & $\begin{array}{l}7.0 \\
(6.0-8.5)\end{array}$ & NS & $\begin{array}{l}8.5 \\
(6.5-9.5)\end{array}$ & $\begin{array}{l}8.0 \\
(6.0-10.0)\end{array}$ & $\mathrm{NS}$ & NS \\
\hline Positive SCR (\%) & $17(68.0)$ & $18(69.2)$ & NS & $78(82.1)$ & $70(68.6)$ & NS & NS \\
\hline
\end{tabular}


Table 3

Sensitivity, specificity, PPV, and NPP of McGill oximetry score and ODI in obese and non-obese subjects.

\begin{tabular}{|c|c|c|c|c|}
\hline & Sensitivity & Specificity & PPV & NPV \\
\hline \multicolumn{5}{|l|}{ ODI > 4/h: } \\
\hline All obese $^{\mathrm{a}}$ & $72 \%$ & $41 \%$ & $68 \%$ & $46 \%$ \\
\hline $\begin{array}{l}\text { Obese mild-to-moderate } \\
\text { OSAS (ie, AHI } \geq 2 \text { to }<10 \\
\text { episodes/h) }\end{array}$ & $73 \%$ & $37 \%$ & $60 \%$ & $51 \%$ \\
\hline $\begin{array}{l}\text { Obese with moderate to } \\
\text { severe OSAS (ie, AHI } \geq 5 \\
\text { episodes/h) }\end{array}$ & $84 \%$ & $44 \%$ & $50 \%$ & $81 \%$ \\
\hline Non-obese children & $58 \%$ & $48 \%$ & $79 \%$ & $21 \%$ \\
\hline \multicolumn{5}{|l|}{ McGill oximetry score $(\geq 2)$ : } \\
\hline Obese & $14 \%$ & $83 \%$ & $47 \%$ & $48 \%$ \\
\hline Non-obese & $15 \%$ & $100 \%$ & $100 \%$ & $56 \%$ \\
\hline \multicolumn{5}{|c|}{$\begin{array}{l}\text { Abbreviations: AHI, apnea-hypopnea index; NPV, negative predictive value; ODI, oxygen } \\
\text { desaturation index; OSAS, obstructive sleep apnea syndrome; PPV, positive predictive value. } \\
\text { a Very minimal OSAS (ie, ranging between } \geq 1 \text { and }<2 \text { events } h \text { ) were excluded. }\end{array}$} \\
\hline
\end{tabular}


Figure legends

Figure 1: Box and whisker plot showing the difference of ODI among the obese and non-obese subgroups 


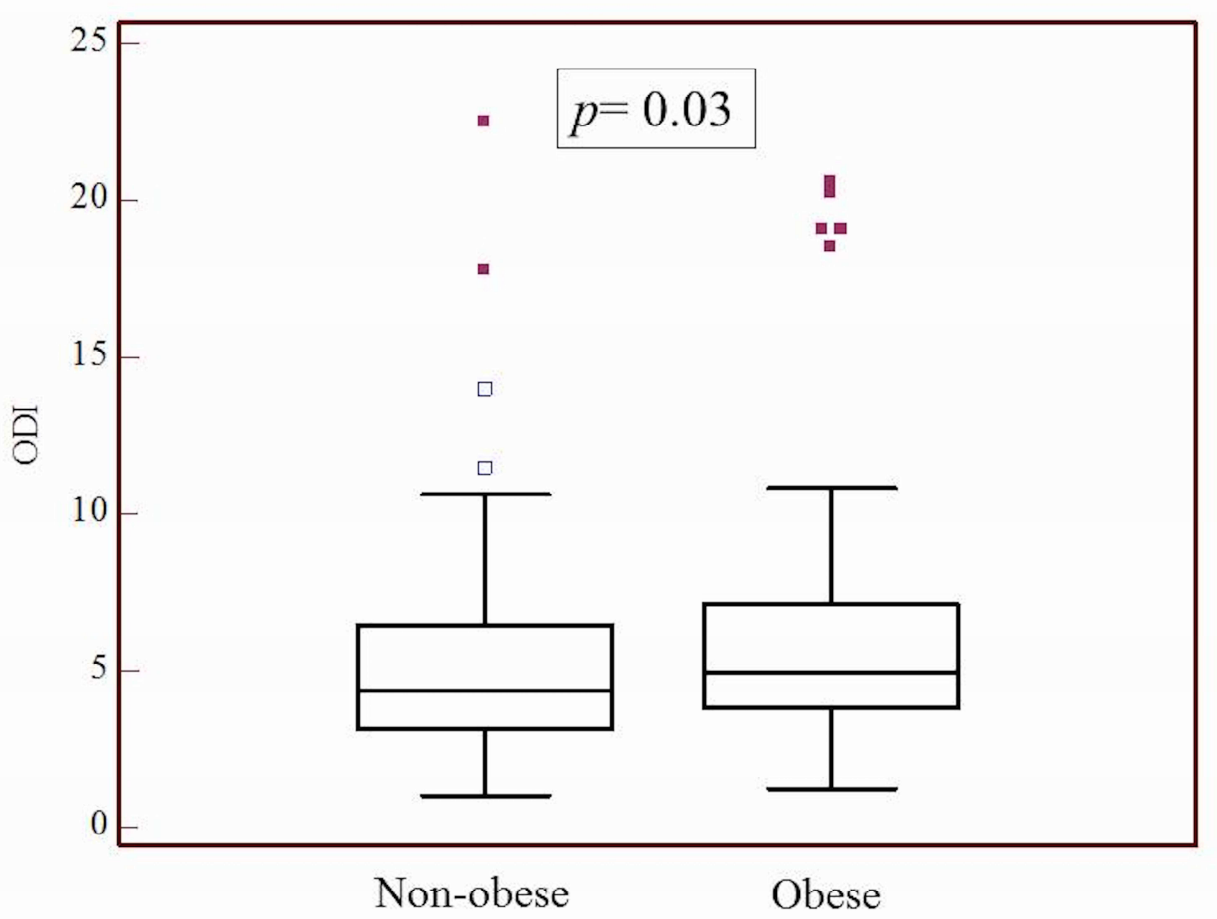




\section{Highlights}

- Obesity is an important risk factor for obstructive sleep apnea syndrome.

- Obese children with obstructive sleep apnea frequently showed oxygen desaturation.

- It is important to evaluate all craniofacial aspects in obese children who snore. 